LIAMES 6 - pp. 29-59, Primavera 2006

Francesc Queixalós

$(C N R S, I R D / U n B)^{1}$

Zoraide dos Anjos G. S.

(Universidade Livre de Amsterdam)

\title{
A língua Katukína-Kanamarí
}

\begin{abstract}
Katukina-Kanamari, previously believed to be two different languages, is spoken by about two thousand people on the Juruá, Jutaí and Javarí rivers and their tributaries, south of the Amazon in the Brazilian state of Amazonas. It could be the only extant language of the small Katukina family. Very little is known about its structure, and the article - a product of field work and analysis on both varieties of the language - offers an overview of the main phonological and grammatical features, with emphasis on its syntactically ergative patterning.
\end{abstract}

KEYWORDS Amazonian language; Katukina-Kanamari; Phonology, Morphosyntax; Ergativity; Dialectology.

RESUMO: A língua Katukína-Kanamarí, anteriormente considerada como duas línguas diferentes, é falada por cerca de duas mil pessoas nos rios Juruá, Jutaí e Javarí e seus tributários, ao sul do rio Solimões, estado do Amazonas, Brasil. Poderia ser a única língua sobrevivente da família Katukina. Pouco se sabe sobre sua estrutura, e o artigo - resultado do trabalho de campo e da análise de ambas as variedades da língua - apresenta uma visão geral dos traços fonológicos e gramaticais, enfatizando o padrão sintaticamente ergativo da língua.

PALAVRAS-CHAVE: Línguas Amazônicas; Katukína-Kanamarí; Fonologia; Morfossintaxe; Ergatividade; Dialetologia.

\section{INTRODUÇÃO}

Este texto é uma apresentação dos traços básicos da língua Katukína-Kanamarí, falada no estado do Amazonas, Brasil, tais como identificados durante uma pesquisa em andamento realizada pelos autores tratando-se, pois, de uma língua pouco estudada até hoje. A correlação de duração na fonologia das vogais desemboca, em um dos dialetos, na criação de ditongos. Traços tais como: escassas morfofonologia e morfologia, a distinção clara entre nomes e verbos, a marcação do núcleo, a ordem de constituintes como AGT-VRB-PAC e como VRB-UNC ${ }^{2}$, o alinhamento básico ergativo em termos de

\footnotetext{
${ }^{1}$ Centre d'études des langues d'Amérique (CNRS, IRD) \& Laboratório de Línguas Indígenas (UnB).
} 
codificação, a constituência e o comportamento, além da transitividade cindida são alguns dos traços básicos que fazem essa língua digna de atenção em termos de tipologia geral, principalmente no que tange à organização das relações gramaticais.

\section{LOCALIZAÇÃO}

A língua é falada por dois grupos que se identificam como povos diferentes e são assim identificados na literatura: os Katukína e os Kanamarí.

Os índios Katukína estão situados nos cursos do rio Biá, que é afluente do rio Jutaí, e do rio Ipixuna, tributário do rio Biá. De acordo com os dados da OPAN (2000) e Lima \& Py-Daniel(2002) eles eram, nessa época, cerca de duzentas e noventa habitantes distribuídos pela Terra Indígena Rio Biá. Informações fornecidas pelos funcionários do convênio FUNASA/Uni-Tefé mostram que a população aumentou, nos últimos cinco anos, para aproximadamene quatrocentos habitantes.

Já os índios Kanamarí estão espalhados por uma área de grande extensão geográfica dentro do estado do Amazonas: do rio Purús ao rio Javarí, e do rio Japurá aos limites do estado do Amazonas com o estado do Acre, com uma dispersão considerável de pequenos grupos locais. Ribeiro et al. (1989) referem-se a dezenove grupos, com uns mil indivíduos no total. Sobre a base de documentos do CEDI-ISA (os sucessivos Povos Indígenas no Brasil) e levantamentos da FUNAI (1988), foi possível contar até mais de trinta grupos, com um total que beira os mil e quinhentos indivíduos.

O caso dos Katawixí merece comentário à parte. O padre Constant Tastevin, em seus manuscritos de quase um século, assinala a presença dos Katawixí no rio Biá e no baixo rio Juruá. Alguns autores consideram-nos extintos (Ribeiro et al.1989). Já informações mais recentes, coletadas por funcionários da FUNAI, parecem confirmar a existência de um grupo isolado na área Jacareuba/Katawixí, situada no rio Mucuim, afluente do rio Purus.

\section{CLASSIFICAÇÃO}

"Katukína" designa, na literatura, três noções distintas: um grupo lingüístico da família Pano, um grupo lingüístico da família Aruák, e uma pequena família composta, por sua vez, de três variedades lingüísticas supostamente diferenciadas o suficiente para merecer a denominação de "línguas": Katukína, Kanamarí e Katawixí (Rivet 1920, Loukotka, 1949, 1963; Tovar 1961).

Existe uma hipótese recente de parentesco genético entre a família Katukína e uma língua isolada da Amazônia Peruana, o Harakmbut ou Amarakaeri, proposta por Adelaar (2000). Se a hipótese, feita com base em material lexical, viesse a se confirmar, novas perspectivas de análise comparativa seriam abertas sobre essa família até agora estritamente brasileira.

\footnotetext{
${ }^{2}$ VRB: verbo, AGT: agente, PAC: paciente, UNC: participante único de verbo monovalente.
} 
A família Katukína, segundo Loukotka (1963) - que baseia sua classificação nas informações de Tastevin (1920b) e Paul Rivet (1920) - é composta por oito línguas que estão divididas em línguas do sul e do norte, a saber:

\begin{tabular}{|l|l|}
\hline Línguas do Sul & Língua do Norte \\
\hline Catuquina ou Wiri-dyapá & \\
Canamari & \\
Prawa ou Hon-dyapá & Catauxi ou Catosé ou Hewadie ou \\
Tucundiapa ou Mangeroma & Katawishi ou Quatausi \\
Bendiapa & \\
Tawari ou Kadekili-dyapa ou Kayarára & \\
Buruá & \\
\hline
\end{tabular}

Os próprios índios identificam, dentro de sua sociedade, segmentos que podemos assimilar a clãs, cuja denominação genérica é dyapa, e da qual se desconhece se reflete ou não algum tipo de subdivisão lingüística. Com base no registro dos dyapa feito por Tastevin para classificar os grupos de índios Katukína e Kanamarí de acordo com sua localização geográfica, Loukotka inferiu, erroneamente, que cada dyapa possuía uma língua distinta. Convém salientar que embora o trabalho do padre Tastevin considere que há, com efeito, diferenças entre o Katukína e o Kanamarí, o que resulta da subdivisão em diferentes dyapa é uma distribuição geográfica.

Por conseguinte, a organização da família Katukína proposta por Loukotka não deve ser considerada uma classificação lingüística propriamente dita. Contudo, a separação entre línguas do sul e do norte, proposta por ele, deveria levar-nos a observar mais atentamente o Katawixí, que parece ser mais distante das outras variedades dentro da família.

A classificação de Rodrigues (1986:79) retoma, entre outros, dados recolhidos pelo ornitólogo Von Spix em 1840, que consistem em uma lista de vocábulos da língua Katukína publicada por Martius (1864). Esse trabalho identifica como membros da família as línguas Katukína (no Biá), Txunhuã-dyapa (entre o Jutaí e o Jandiatuba), Kanamarí (no Juruá, Xeruâ, Tarauacá, Itaquaí e Jutaí) e Katawixí possivelmente extinto.

Os arquivos da sede da Congregação do Santo Espírito em Chevilly-Larue perto de Paris, os do Professor Paul Rivet no Museu do Homem de Paris, assim como os da Prelazia de Tefé, município do Amazonas, contém importantes documentos do Padre Constant Tastevin sobre vários desses grupos e línguas. No que se refere aos dados sobre Katawixí, os arquivos de Chevilly-Larue detêm um vocabulário recolhido por Tastevin junto aos poucos remanescentes encontrados por ele em 1920 (1920a). Trata-se de uma lista com cerca de duzentas palavras e algumas sentenças. Posteriormente, em 1926, entretanto, Tastevin relata que os índios já haviam desaparecido.

Desde essa época não se encontram relatos da existência de uma comunidade lingüística Katawixí. Para Ribeiro et al (1989) esses índios estariam extintos. Günter Kroemer (apud Neves, 1996) acredita que estariam reduzidos a um número de dez falantes. Neves, por sua vez, afirma que esses índios já não falam mais a língua. Embora haja menção por funcionários da FUNAI de índios Katawixí isolados que se encontrariam na Terra Indígena Jacareuba/Katawixí no rio Mucuim, ao norte da cidade de Porto Velho, 
estado de Rondônia, não há registros confirmando a existência de índios Katawixí na atualidade.

Tastevin incluía os tyohon dyapa entre os clãs Kanamarí, e relata que viviam na bacia do Jutaí, mais ao oeste, no rio Itewahy, afluente do Jawary e do Jandiatuba, tributários do rio Juruá (sic). Entretanto, não fornece dados sobre a língua falada por eles. As informações mais recentes são de que um grupo de tyohon dyapa foi contatado em 2001 pela expedição da FUNAI liderada por Sidney Possuelo na região entre os rios Jutaí e Jandiatuba. Trata-se de um grupo dominado pelos Kanamarí, que lhes presta serviços em troca de comida e roupas. Não são considerados índios isolados pelos funcionários da FUNAI, pois mantêm contato com a sociedade não-índia por meio dos Kanamarí que lhes fornecem ferramentas e alimentos vindos das cidades próximas.

Tastevin já afirmava em 1920 (1920a) que ao se falar em Kanamarí e Katukína do Biá não falamos de duas línguas, mas sim de duas variedades de uma mesma língua: "La langue de ces Katukína est essentiellement la même que celle des Kanamarí avec certaines particularités dialectales qui s'expliquent aisément par leur isolement".

Nossas observações no campo e a análises dos dados lingüísticos confirmam plenamente essa afirmação do missionário. Como exemplo, em julho de 2005, devido a problemas de transporte, cerca de trinta índios Kanamarí do alto Jutaí ficaram na aldeia Katukína Boca do Biá por aproximadamente dois meses. Os Katukína do Biá dizem que essa foi a primeira vez que viram os Kanamarí do Jutaí. Embora de lado a lado fosse um fato reconhecido a existência de algumas diferenças, basicamente lexicais, todos admitiam que a comunicação entre os dois grupos ocorria de forma perfeitamente fluida. No presente artigo são mencionados alguns dos traços fonológicos, gramaticais, discursivos e lexicais que nos permitem afirmar a condição de dialetos da mesma língua no que diz respeito às, até hoje, chamadas de língua Katukína e língua Kanamarí. Outrossim, há uma forte presunção, com base nas nossas observações de campo, de que o tyohon dyapa seja uma subvariedade do dialeto Kanamarí. Em síntese, na suposição de que exista hoje em algum lugar da Amazônia falantes de Katawixí, consideramos que a família Katukína é composta de duas línguas, dando a mais importante delas em termos demográficos a denominação de Katukína-Kanamarí, ou, simplesmente, Katukína. Dessa língua, a variedade Katukína é falada no rio Biá (Dos Anjos: 2005), enquanto a variedade Kanamarí é falada principalmente nos cursos dos rios Juruá, Japurá, Xeruã, Itaquaí e Jutaí (Ribeiro et al 1989; Lima \& Py-Daniel, 2002).

A situação, para a maioria dos grupos, é de contato permanente ou semi-permanente com a sociedade nacional, com exceção de uns poucos grupos reputados arredios ou isolados (cabeceiras do Pentiaquinho, afluente do Ituí; cabeceiras do rio Branco, afluente do Itaquaí; igarapé Kanamarí, afluente do Arama; cabeceiras dos Jandiatuba e Jutaizinho; FUNAI e CEDI-ISA). 


\section{ESTUDOS}

O conhecimento sobre essa família lingüística é escasso. Fora a série de artigos de Constant Tastevin e Paul Rivet, que data da década dos anos vinte do século passado (cf. bibliografia), até a entrada dos autores do presente texto os estudos concentraram-se sobre o dialeto Kanamarí: quatro artigos de uma missionária da organização New Tribes Mission versam sobre pontos de gramática (Groth 1977, 1985, 1988a, 1988b), e um artigo sobre fonologia produzido por uma equipe liderada pelo antropólogo Márcio Silva (Ribeiro et al.1989).

Pesquisas realizadas em arquivos franceses pelos autores do presente texto (Fonds Paul Rivet, Musée de l'Homme de Paris, 1994; Archives des Pères du Saint-Esprit, Chevilly-Larue, 2002, 2005) permitiram obter cópias de trabalhos de considerável importância lingüística e antropológica: dois manuscritos de vocabulários de autoria do padre Constant Tastevin, um contendo dados das variedades Kanamarí, Katukína e Katawixí, o outro sobre o Katawixí (e o Marawá, língua Arawak). O segundo traz também farta informação etnográfica sobre os Katawixí (tradição oral, cultura material) ${ }^{3}$.

Dos Anjos realizou oito períodos de trabalhos de campo nos anos de 2003-2006, junto aos índios Katukína do Biá. As aldeias visitadas foram Pilão, Janela, Gato e Boca do Biá. Essas aldeias estão situadas às margens do rio Biá, afluente do rio Jutaí, e fazem parte da terra indígena Rio Biá. Ela concentrou-se sobre a fonologia do dialeto do Biá (Dos Anjos 2005a, 2005b) e atualmente trabalha na elaboração de uma gramática descritiva da língua, no programa de doutorado em lingüística da Universidade Livre de Amsterdam, Holanda. Queixalós desenvolveu pesquisa de campo entre os índios Kanamarí do rio Itaquaí (Massapê, terra indígena Vale do Javari) de 1994 a 1998. De 2003 a 2006, realizou trabalhos de campo junto aos índios Katukína do Biá, nas aldeias Gato e Boca do Biá. Estuda o fenômeno da ergatividade focado na tipologia das relações gramaticais, nos planos sincrônico e diacrônico. Tem publicado sobre pontos de gramática, principalmente relativos ao tema da ergatividade, levando em conta os dois dialetos (rios Itaquai e Biá) (Queixalós 1995, 2002a, 2002b, 2003, 2004, 2005).

No que se refere aos estudos etnográficos, sobre os Kanamarí existem três teses de doutorado, Santos (2002), Carvalho (1998) e Reesink (1993), e duas dissertações de mestrado, Labiak (1997) e Neves (1996). Há, ainda, um artigo de Monteiro (2002) sobre a demarcação das terras indígenas Kanamarí. Sobre Katukína do Biá há um relatório produzido pela antropóloga Deborah Lima e pelo biólogo Vitor Py-Daniel (2002), ressaltando aspectos da demografia e da organização político-econômica da sociedade Katukína do Biá. Atualmente está sendo preparada uma tese de doutorado sobre as populações do Biá pelo antropólogo Jeremy Deturche.

\footnotetext{
${ }^{3}$ Cópias desses documentos constituem, atualmente, parte do acervo do Laboratório de Línguas Indígenas da Universidade de Brasília.
} 


\section{FONOLOGIA}

Nesta seção apresentamos a organização básica do sistema fonológico, com uma hipótese diacrônica destinada a explicar uma diferença entre os dois dialetos que afeta o sistema das vogais.

\subsection{Fonemas}

\subsubsection{Consoantes}

Os fonemas consonantais, em número de quatorze, estão organizados em dois subsistemas: o primeiro é formado pelos segmentos obstruintes e o segundo pelos segmentos soantes, como podemos observar no quadro seguinte, que representa a parte central do sistema:

\begin{tabular}{|c|c|c|c|}
\hline \multirow{2}{*}{ obstruintes } & labial & alveolar & palatal \\
\cline { 2 - 4 } & $\mathrm{p}$ & $\mathrm{t}$ & $\mathrm{t}$ \\
\cline { 2 - 4 } & $\mathrm{b}$ & $\mathrm{d}$ & $\mathrm{d} 3$ \\
\hline \multirow{3}{*}{ soantes } & $\mathrm{m}$ & $\mathrm{n}$ & $\mathrm{n}$ \\
\cline { 2 - 4 } & $\mathrm{w}$ & 1 & $\mathrm{j}$ \\
\hline
\end{tabular}

O traço vozeamento subdivide as obstruintes; o traço nasalidade subdivide as soantes.

Na periferia do sistema temos dois fonemas posteriores, ambos surdos: um oclusivo velar, $\mathbf{k}$, e um fricativo glotal, $\mathbf{h}$.

Ilustramos a seguir algumas das oposições entre fonemas consonânticos ${ }^{4}$.

\begin{tabular}{|c|c|c|c|c|}
\hline $\begin{array}{l}\text { p } \\
\text { b }\end{array}$ & $\begin{array}{l}\text { pa:da } \\
\text { ba:da }\end{array}$ & $\begin{array}{l}\text { 'cuia' } \\
\text { 'catipuru' }\end{array}$ & $\begin{array}{l}\text { kupa } \\
\text { u:ba }\end{array}$ & $\begin{array}{l}\text { 'paxiubinha' } \\
\text { 'tabaco' }\end{array}$ \\
\hline $\mathbf{t}$ & tun & 'cesto' & ti:ti & 'lavar' \\
\hline d & dun & 'peixe' & ti:di & 'atravessar' \\
\hline $\mathbf{t} \int$ & $\mathrm{t} \int \mathrm{an}$ & 'sol' & {$[\ldots]$} & \\
\hline d3 & dzan & 'caminho' & {$[\ldots]$} & \\
\hline $\mathbf{t}$ & to: & 'descansar' & kitana & 'socó' \\
\hline t $\int$ & t $\int 0:$ & 'pupunha' & 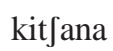 & 'gato do mato \\
\hline
\end{tabular}

${ }^{4}$ Os exemplos ilustrando a seção de fonologia procedem do dialeto do Biá. [...] indica distribuição defectiva ou lacuna nos dados. 
QueIXAlós \& Anjos: A língua KatukínA-KanAmari

\begin{tabular}{|c|c|c|c|c|}
\hline $\begin{array}{l}\text { d } \\
\text { d3 }\end{array}$ & $\begin{array}{l}\text { dan } \\
\text { dzan }\end{array}$ & $\begin{array}{l}\text { ‘assar’ } \\
\text { ‘caminho’ }\end{array}$ & $\begin{array}{l}\text { pa:da } \\
\text { pa:dza }\end{array}$ & $\begin{array}{l}\text { 'cuia' } \\
\text { 'tamanduá' }\end{array}$ \\
\hline m & makuna & 'cará' & wamulu & 'matrinxã' \\
\hline n & nukunana & 'tucunaré' & wanama & 'macaco mambira' \\
\hline $\mathbf{n}$ & nan & 'carapanã' & mana & 'procurar' \\
\hline j & na & ‘seio’ & mana & 'grande' \\
\hline n & {$[\ldots]$} & & manulu & 'mosca' \\
\hline 1 & {$[\ldots]$} & & malu & 'tatu’ \\
\hline $\mathbf{j}$ & {$[\ldots]$} & & majan & 'parentes' \\
\hline n & {$[\ldots]$} & & maja & 'grande' \\
\hline d3 & {$[\ldots]$} & & wadza & 'lua' \\
\hline $\mathrm{n}$ & {$[\ldots]$} & & ana & 'mulher' \\
\hline b & bamak & ‘pacu’ & bibik bibik & 'trovejar' \\
\hline $\mathbf{w}$ & wamuk & 'esposa' & bi:wik & 'chupar' \\
\hline d & {$[\ldots]$} & & ku:di & 'tomar banho' \\
\hline 1 & {$[\ldots]$} & & u:li & 'corda' \\
\hline b & bala & 'caça' & & \\
\hline m & malu & ‘tatu’ & & \\
\hline $\mathbf{k}$ & ki: & ‘cabeça' & bakun & ‘dedo da mão’ \\
\hline h & hi:wan & 'chamar' & mahuki & 'avisar' \\
\hline
\end{tabular}

\subsubsection{Vogais}

Três traços identificam quatro unidades básicas: i, u, u, a, distribuídas assim:

$\begin{array}{lllll}\text { abertura: } & \text { alto } & \mathrm{i}, \mathrm{u}, \mathrm{u} & \text { baixo } & \mathrm{a} \\ \text { língua: } & \text { anterior } & \mathrm{i} & \text { posterior } & \mathrm{u}, \mathrm{u} \\ \text { lábios: } & \text { arredondado } & \mathrm{u} & \text { não arredondado } & \mathrm{i}, \mathrm{u}\end{array}$

Os seguintes exemplos justificam a existência dos três fonemas altos:

$\begin{array}{lll}\mathbf{i} & \mathrm{pi} & \text { 'espinho' } \\ \mathbf{u} & \mathrm{pu} & \text { 'ovo' } \\ \mathbf{u} & \mathrm{pu} & \text { 'comer' }\end{array}$


$\begin{array}{lll}\mathbf{i} & \text { bakti } & \text { 'perto' } \\ \mathbf{u} & \text { baktu } & \text { 'ruim' }\end{array}$

\subsection{Sílaba}

Podemos resumir a estrutura silábica por meio da fórmula geral $\left(\mathbf{C}_{1}\right) \mathbf{V}_{1}\left(\mathbf{V}_{2}\right)\left(\mathbf{C}_{2}\right)$, na qual $\mathbf{V}$ é o elemento constituinte do núcleo silábico, que pode ser simples $\mathbf{V}_{1}$, ou complexo $\mathbf{V}_{1} \mathbf{V}_{2} ; \mathbf{C}_{1}$ representa a consoante em posição de ataque silábico; e $\mathbf{C}_{2}$ representa a consoante que ocupa a posição de coda silábica.

Todas as consoantes ocupam a posição de ataque silábico. Alguns exemplos:

$\begin{array}{lllll}\mathbf{p} & \text { piya } & \text { 'homem' } & \text { wa:po } & \text { 'pronto' } \\ \mathbf{t} & \text { tu:li } & \text { 'cesto de cipó' } & \text { ita } & \text { 'fogo' } \\ \mathbf{t f} & \text { t } \text { wuku } & \text { 'morrer' } & \text { bat } 5 \mathrm{i} & \text { 'veado' } \\ \mathbf{k} & \text { kawadzu } & \text { 'coati' } & \text { walikama } & \text { 'capivara' } \\ \mathbf{b} & \text { ba:da } & \text { 'catipuru' } & \text { obawa } & \text { 'dois' } \\ \mathbf{d} & \text { dun } & \text { 'peixe' } & \text { pa:da } & \text { 'cuia' } \\ \mathbf{d 3} & \text { dzuku } & \text { 'pedra' } & \text { hu:dza } & \text { 'macaco mambira' } \\ \mathbf{m} & \text { mimi } & \text { 'sangue' } & \text { kamudza } & \text { 'macaco barrigudo' } \\ \mathbf{n} & \text { na:t } 5 \mathrm{i} & \text { 'milho' } & \text { buni } & \text { 'furar' } \\ \mathbf{n} & \text { na } & \text { 'seio' } & \text { mana } & \text { 'grande' } \\ \mathbf{l} & {[\text {...] }} & & \text { wa:lu } & \text { 'papagaio' } \\ \mathbf{h} & \text { hai } & \text { 'carne' } & \text { mahuki } & \text { 'avisar' } \\ \mathbf{w} & \text { wili } & \text { 'queixada' } & \text { mawi } & \text { 'preguiça' } \\ \mathbf{j} & \text { jalikun } & \text { 'jaraqui' } & \text { kapaju } & \text { 'mamão' }\end{array}$

O fonema I não aparece em início de palavra. 
Em posição de coda figura apenas a classe das oclusivas surdas, representada pelo arquifonema $\mathbf{K}$, e a classe das nasais, representada pelo arquifonema $\mathbf{N}$.

$\begin{array}{lllll}\mathbf{K} & \text { haK } & \text { 'casa' } & \text { hiKna } & \text { 'ver' } \\ \mathbf{N} & \text { kitaN } & \text { 'dormir' } & \text { udzaNka } & \text { 'fruta amarga' }\end{array}$

Todas as vogais podem constituir um núcleo silábico simples:

ba 'folha' pi 'espinho pu 'ovo' buK 'fazer'

Núcleos complexos são formados de:

1) duas vogais idênticas (grafadas como v:):

$\begin{array}{llll}\text { wa:pa } & \text { 'cachorro' } & \text { ki:wa } & \text { 'paca' } \\ \text { u:maN } & \text { 'árvore' } & \text { wu:lu } & \text { 'garganta' }\end{array}$

2) duas vogais diferentes. As seqüências atestadas são ai, oi, au.

ki:dai 'cabelo' woikaN 'remar' taukala 'galinha'

\subsection{Acento}

A grande maioria das palavras se encaixa no padrão oxítono:

$\begin{array}{ll}\text { i't } \int u n & \text { 'arco' } \\ \text { wu:'luu } & \text { 'garganta' } \\ \text { mana'ti } & \text { 'noite' } \\ \text { woi'kan } & \text { 'remar' } \\ \text { ma:pi'kan } & \text { 'escutar' } \\ \text { wapika'lu } & \text { 'boto' }\end{array}$

O acréscimo de sufixos leva o acento a se deslocar para o fim da palavra:

$\begin{array}{ll}\text { ki'taN } & \text { 'dormir' } \\ \text { kitaN-'niN } & \text { 'dormindo }\end{array}$

Esse fenômeno parece não acontecer em todos os casos. O estudo sistemático da colocação do acento em função da concatenação dos morfemas está ainda por se fazer. 


\subsection{Realizações}

Aqui apresentamos alguns traços interessantes relativos à pronúncia das unidades fonológicas.

\subsubsection{Consoantes}

Ataques silábicos que não sejam preenchidos por um dos fonemas consonânticos apresentados acima podem, opcionalmente, realizar-se como oclusão glotal.

$$
\text { [?u:ba] 'tabaco' [tu:?u] 'outro' }
$$

O arquifonema K (ou seja, a classe das oclusivas surdas) se realiza como velar não explodido 5 .

\begin{tabular}{|c|c|c|}
\hline /wakaK/ & $\rightarrow$ & [wakak ] \\
\hline /hiKna/ & $\rightarrow$ & [hik`na] \\
\hline
\end{tabular}

O arquifonema $\mathbf{N}$ (ou seja, a classe das nasais) tem uma realização fonética velar.

$$
\begin{aligned}
& \text { /miN/ } \rightarrow \quad \text { [min] }] \text { 'barriga' } \\
& / \text { taNti } \rightarrow \text { [tãnti] 'aqui' }
\end{aligned}
$$

\subsubsection{Vogais}

As vogais altas i e u têm um amplo leque de variação livre na escala de abertura. Cabe aqui distinguir o caso dos núcleos silábicos simples do caso dos núcleos complexos. Os primeiros apresentam três graus de abertura:

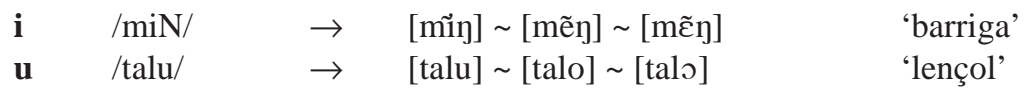

Os núcleos complexos isovocálicos experimentam uma dissimilação dos seus componentes: o primeiro elemento percorre todos os graus de abertura:
i: $\quad / \mathrm{i}: \mathrm{ku}$
$\rightarrow \quad[$ iiko $] \sim[$ eiko $] \sim[$ [iko] $\sim[$ aiko $]$
'olho'
u: /u:pu/
$\rightarrow \quad$ [uupu $] \sim$ [oupu] [ [oupu] $\sim$ [aupu $]$ 'filhote'

Duas assimetrias na dissimilação desses núcleos devem ser mencionadas:

\footnotetext{
${ }^{5}$ Nesta seção sobre realizações, só será ilustrado o fenômeno em questão.
} 
1) no anterior, a dissimilação se estende à posição da língua: o primeiro elemento se posterioriza e, por conseqüência, inicia um processo de fechamento.

i: $\quad / \mathrm{i}: \mathrm{ku} / \quad \rightarrow \quad \ldots \sim[$ jiko] $\sim[$ oiko] 'olho'

2) no posterior, a realização longa tem contrapartidas abertas:

u: $\quad / \mathrm{u}: \mathrm{pu} / \rightarrow \quad \ldots \sim[\mathrm{o}: \mathrm{pu}] \sim[\mathrm{o:pu}] \quad$ 'filhote'

É importante salientar que a ditongação opcional dos núcleos complexos isovocálicos é uma inovação diacrônica exclusiva do dialeto do Biá. O Kanamarí mantém intacta a realização uniforme desses núcleos.

A outra característica da realização das vogais é sua nasalização em sílaba com coda nasal, fenômeno que propicia o apagamento da consoante.

/paN/ $\rightarrow$ [pãg] $\sim[\mathrm{pã}] \quad$ 'braço'

\subsubsection{Acento}

O correlato fonético do acento é a altura do tom fundamental (para ilustrações acústicas, cf. Dos Anjos 2005b).

\section{ESTRUTURA BÁSICA DA ORAÇÃO}

A oração se constrói em torno de um constituinte formado pelo predicado e seus argumentos, sendo estes entendidos como a manifestação formal dos participantes requeridos pela estrutura semântica do predicado. Três tipos de predicado podem ser identificados, dependendo da classe léxica da palavra que aparece na posição de núcleo de predicado: verbal, nominal, e adverbial. Na sequiência da fala, e em ausência de rearranjos motivados pragmaticamente, o constituinte predicativo aparece primeiro, seguido do seu argumento externo.

predicado verbal ${ }^{6}$

$\begin{array}{ll}(1)^{\mathrm{ITQ}} & \text { kitan } \quad \text { wa:pa } \\ & \begin{array}{l}\text { Dormir } \\ \text { 'o cachorro dorme' }\end{array}\end{array}$

${ }^{6}$ Os exemplos ilustrando esta seção mencionam sua procedência dialetal: ITQ indica o dialeto Kanamarí tal como falado no Itaquai, BIA indica o dialeto Katukína do Biá. Daqui em diante, as seguintes convenções gráficas serão utilizadas: $/ \mathbf{t} \mathbf{f} / \rightarrow \underline{\mathbf{t y}}, / \mathbf{d} \mathbf{3} / \rightarrow \underline{\mathbf{d y}}, / \mathbf{j} / \rightarrow \underline{\mathbf{n y}}, / \mathbf{j} / \rightarrow \mathbf{y}, / \mathbf{l} / \rightarrow \underline{\mathbf{r}}, / \mathbf{K} / \rightarrow \underline{\mathbf{k}}, / \mathbf{N} / \rightarrow \underline{\mathbf{n}}$, $/ \mathbf{u} / \rightarrow \underline{\mathbf{u}}, / \mathbf{u} / \rightarrow \underline{\mathbf{0}}$ 
predicado nominal

$(2)^{\mathrm{ITQ}} \quad$ tukuna idi:k

Humano Você

'você é um ser humano'

predicado adverbial

(3) $)^{\mathrm{ITQ}}$ kodo kamodya

EmCima Macaco Sp.

'o macaco sp. está lá em cima'

Esses são exemplos de predicados monovalentes. Cada tipo de predicado tem uma contrapartida divalente, ou seja, com dois argumentos.

predicado verbal

$\begin{array}{llll}(4)^{\text {BIA }} & \text { Maria-na } & \text { dyuman } & \text { tahi } \\ & \text { Maria-CasoM } & \text { Derramar } & \text { Água } \\ \text { 'Maria derramou a água' } & \end{array}$

predicado nominal

$\begin{array}{llll}(5)^{\text {ITQ }} & \text { Nodia-na } & \text { obatyawa } & \text { Owi } \\ & \text { Nodia-CasoM } & \text { Esposa } & \text { Owi }\end{array}$

'a Owi é a esposa do Nodia'

predicado posposicional (considerado como uma subclasse de predicado adverbial)
(6) ${ }^{\text {BIA }}$ Yako-na katu
Dyuraidi
Yako-CasoM ComitativoInstrumental Dyuraidi
'a Dyuraidi está com o Yako'

Os predicados divalentes são de núcleo final, e apresentam um argumento externo com as mesmas propriedades do argumento externo do predicado monovalente - posição pós-predicativa, não marcação de caso —, e um argumento interno ao sintagma predicativo, marcado pelo sufixo de caso -na (o "CasoM" das glosas. Na pronúncia, o sufixo de caso se procliticiza ao núcleo). A comparação entre (4) e (1) revela um alinhamento de tipo ergativo no que tange à posição relativa dos constituintes e à morfologia nominal. O caso marcado inclui o que seriam o caso ergativo, (4), o caso genitivo, (5), e o caso do complemento de posposição, (6).

Cabe mencionar também uma construção verbal divalente bem menos freqüente do que a construção ergativa de (4): 


\section{$(7)^{\text {BIA }}$ nokonana hak Ayobi \\ PeixeSp. Flechar Ayobi \\ 'o Ayobi flechou peixe sp.'}

O predicado é também de núcleo final. O sintagma nominal Ayobi em (7) tem as mesmas propriedades que o argumento externo nas construções divalentes (4)-(6). O outro sintagma nominal, nokonana, é interno ao sintagma predicativo, mas não leva marca de caso. Se compararmos as construções (7) e (1), observamos que elas manifestam um alinhamento de tipo acusativo. A motivação para a construção verbal divalente acusativa parece, nesta fase de nossa análise da língua, residir nas propriedades semânticas do participante que em (7) se encontra no papel de "flechado": a sua referência é genérica. Nessa cisão das construções verbais divalentes, a estrutura de padrão ergativo ilustrada em (4) deve ser considerada básica.

Todo argumento externo tem a faculdade de ser deslocado para a esquerda do sintagma predicativo. A motivação deste movimento, presumivelmente pragmática, não foi ainda bem elucidada. Exemplos com predicados verbais:

monovalente
$(8)^{\mathrm{I} T}$

$\begin{array}{ll}\text { wa:pa } & \text { kitan } \\ \text { Cachorro } & \text { Dormir }\end{array}$
'o cachorro dorme'

divalente na construção ergativa
(9) ${ }^{\text {BIA }}$ tahi Maria-na dyuman
Água Maria-CasoM Derramar
'a Maria derramou a água'

divalente na construção acusativa

$\begin{array}{lll}(10)^{\text {BIA }} & \text { Ayobi nokonana } & \text { hak } \\ & \text { Ayobi PeixeSp. } & \text { Flechar } \\ & \text { 'o Ayobi flechou peixe sp.' }\end{array}$

Todo argumento externo tem a faculdade de ser apagado quando seu referente é recuperável pelo contexto ou pela situação.
$(11)^{\mathrm{ITQ}} \quad$ wa
hinuk-na
tohi:k
niama
Mulher Grupo-CasoM Ver
Então
'aí as mulheres o viram' 
$\mathrm{O}$ argumento interno marcado para caso não pode ser extraído do constituinte onde figura seu núcleo sem que seu sintagma nominal perca a relação gramatical com o núcleo. Se extraído ou apagado, a marca de pessoa prefixa-se ao núcleo (cf. (13)).

\section{CLASSES DE PALAVRAS E MORFOLOGIA}

Veremos aqui os verbos, nomes, posposições, adjetivos, advérbios e partículas. As três primeiras classes têm em comum a morfologia pessoal em forma de um paradigma de seis prefixos combinando pessoa e número.

$\begin{array}{lll} & \text { singular } & \text { plural } \\ 1^{\circ} & \text { yo- } & \text { tyo- } \\ 2^{\text {o }} & \text { no- } & \text { na- } \\ 3^{\circ} & \text { a- } & \text { ma- }\end{array}$

(A primeira singular tem alomorfismo no dialeto Kanamarí.) Os prefixos pessoais remetem ao referente do argumento interno dos núcleos divalentes. Os núcleos monovalentes não têm morfologia de pessoa.

verbo
$(13)^{\text {BIA }} \quad$ a-dyuman tahi
$3^{\circ}$ Singular-Derramar Água
'ela derramou a água'

nome
$(14)^{\mathrm{ITQ}} \quad$ a-obatyawa $\quad$ Owi
$3^{\circ}$ Singular-Esposa Owi
'a Owi é a esposa dele'

posposição
$(15)^{\text {BIA }} \quad$ a-katu
Dyuraidi
$3^{\circ}$ Singular-ComitativoInstrumental Dyuraidi
'a Dyuraidi está com ele'

A classe dos nomes divalentes inclui termos de parentesco, nomes de partes de um todo, e nomes de entidades necessariamente associadas com outra entidade, tais como wadik "nome", ipori "superfície". 
O inventário das posposições varia levemente entre os dois dialetos, Biá e Kanamarí. Por exemplo, wana, locativo perlativo, não foi registrado nos dados deste último, ao qual pertence a lista a seguir:

$\begin{array}{ll}\text { ama } & \text { 'benefactivo, detrimentário, causa' } \\ \text { han } & \text { 'comitativo' } \\ \text { hon } & \text { 'causa' } \\ \text { iton } & \text { 'privativo' } \\ \text { katu } & \text { 'comitativo, instrumental' } \\ \text { naki } & \text { 'locativo inessivo 1' } \\ \text { ta } & \text { 'locativo inessivo 2 ("no meio de")' } \\ \text { tan } & \text { 'comparativo' } \\ \text { tatan } & \text { 'locativo adessivo' } \\ \text { to } & \text { 'locativo ilativo' } \\ \text { ton } & \text { 'destinatário, instrumental, locativo'. }\end{array}$

Diferenças formais distinguem essas três classes de palavras entre si.

1) $\mathrm{O}$ verbo divalente pode apresentar uma construção diferente de (4) e (13). Uma das circunstâncias em que se recorre a esta construção é a pronominalização por demonstrativo (para outras motivações, cf. Queixalós 2002). Nos exemplos a seguir, observamos que em se tratando do participante "chamado", tal pronominalização se faz por simples substituição lexical.
$(16)^{\mathrm{ITQ}} \quad$ Nodia-na ohoho Owi
Nodia-CasoM Chamar Owi
'o Nodia chamou a Owi'
$(17)^{\mathrm{ITQ}} \quad$ Nodia-na $\quad$ ohoho itiyan
Nodia-CasoM Chamar Aquele
'o Nodia chamou aquele'

A pronominalização por demonstrativo do participante "chamador" só é possível mediante uma mudança radical da construção: o "chamador" capta as propriedades de argumento externo, e o "chamado" deixa de manter uma relação argumental com o núcleo, embora ainda possa aparecer como sintagma nominal não marcado para caso. $\mathrm{O}$ verbo apresenta um prefixo wa- que indica a tal construção antipassiva.
$(18)^{\mathrm{ITQ}} \quad$ itiyan $\quad$ wa-ohoho (Owi)
Esse Antipassivo-Chamar Owi
'esse chamou (a Owi)'

(A posição do argumento externo é tipicamente pós-predicativa. Aqui ele aparece sob forma de demonstrativo, deslocado para a posição pré-predicativa. O "chamado", quando 
ele aparece explicitamente, está ou não acompanhado pela posposição instrumental, podendo estar em posição pré- ou pós-predicativa. Esses pontos não estão bem elucidados ainda).

Em presença do prefixo wa- não é mais possível flexionar o verbo segundo a pessoa. A pessoa, nesse caso, aparece como pronome livre na posição de argumento externo.

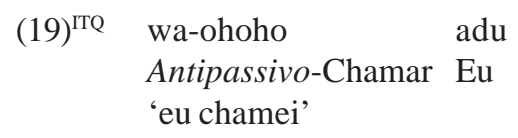

A aptidão, acessibilidade à morfologia antipassiva distingue os verbos divalentes dos nomes divalentes e das posposições.

2) Os verbos, tanto mono - quanto divalentes, podem ser nominalizados.

\begin{tabular}{|c|c|}
\hline$(20)^{\mathrm{ITQ}}$ & $\begin{array}{l}\text { kitan wa:pa } \\
\text { Dormir Cachorro } \\
\text { 'o cachorro dorme' }\end{array}$ \\
\hline$(21)^{\mathrm{ITQ}}$ & $\begin{array}{l}\text { kitan nyan } \\
\text { Dormir Dêitico } \\
\text { 'o dormidor' }\end{array}$ \\
\hline$(22)^{\mathrm{ITQ}}$ & 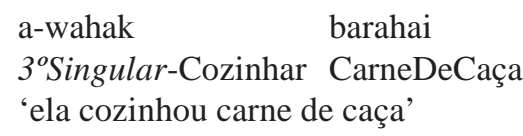 \\
\hline$(23)^{\mathrm{ITQ}}$ & $\begin{array}{ll}\text { a-wahak } & \text { nyan } \\
3^{\circ} \text { Singular-Cozinhar } & \text { Dêitico } \\
\text { 'a coisa cozinhada por ela' }\end{array}$ \\
\hline
\end{tabular}

Um exemplo de nominalização em posição argumental:
$(24)^{\mathrm{ITQ}}$ oba biwik nyan-na wu obakon Fumo Chupar Dêitico-CasoM Querer Cigarro 'o fumador quer o cigarro'

A nominalização não é accessível a nomes nem a posposições.

3) Os nomes recebem o sufixo de caso marcado, -na (cf. (4)-(6)). Eles podem ser substituídos por formas pronominais livres, sejam elas demonstrativas — proximal itowun, distal itiyan (cf. (17)) — ou não: 
(25)

$\begin{array}{lll} & \text { singular } & \text { plural } \\ 1^{\text {o }} & \text { adu } & \text { adi:k } \\ 2^{\text {o }} & \text { idi:k } & \text { idiki } \\ 3^{\text {o }} & \text { anyan } & \text { anyan hinuk }\end{array}$

(Um exemplo de primeira pessoa singular aparece em (19)). A forma de terceira plural é composta pela forma pronominal de terceira singular e o que parece ser um nome coletivo hinuk.

Nem as posposições nem os verbos podem receber marca de caso ou ser pronominalizados.

4) A marca de negação é um sufixo -tu associado ao núcleo de predicado.

$(26)^{\mathrm{BIÁ}} \quad$ wamok-tu

Esposa-Negação

'(ela) não é a esposa (dele)'

$(27)^{\mathrm{ITQ}}$ kitan-tu anyan

Dormir-Negação Ele 'ele não dorme'

(28) ${ }^{\text {ITQ }}$ pi:da-na wu-tu niama tyohi

Onça-CasoM Querer-Negação Então CaiçumaDePupunha

'a onça não quis a caiçuma de pupunha'

(29) ${ }^{\text {BIA }}$ Yako-na katu-tu Dyuraidi

Yako-CasoM ComitativoInstrumenta-Negação Dyuraidi

'a Dyuraidi não está com o Yako'

Outra característica que partilham verbos, nomes e posposições é sua capacidade de constituir sintagmas. $\mathrm{O}$ isomorfismo entre sintagma verbal, sintagma nominal com complemento genitivo, e sintagma posposicional ficou evidente nos exemplos (4)-(6) e (13)-(15), retomados aqui parcialmente com os colchetes ressaltando a constituência:

sintagma verbal
$(30)^{\text {BIA }}$ [Maria-na dyuman] tahi
Maria-CasoM Derramar Água
'[Maria derramou] a água'
$(31)^{\text {BIA }} \quad$ [a-dyuman] tahi
$3^{\circ}$ Singular-Derramar Água
'[ela derramou] a água'


sintagma nominal

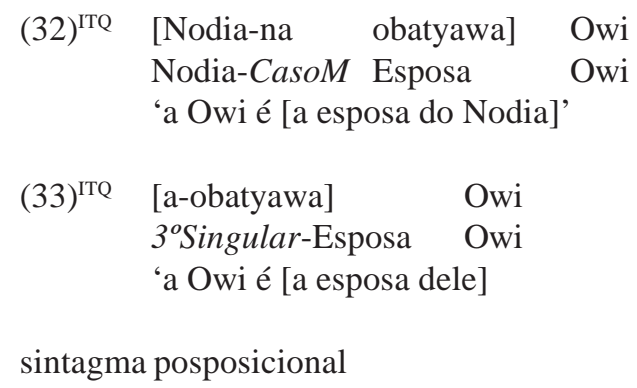

$(34)^{\text {BIA }}$ [Yako-na katu] Dyuraidi

Yako-CasoM ComitativoInstrumental Dyuraidi

'a Dyuraidi está [com o Yako]'

$(35)^{\text {BIA }}$ [a-katu] Dyuraidi

$3^{\circ}$ Singular-ComitativoInstrumental Dyuraidi

'a Dyuraidi está [com ele]'

É interessante salientar que o dialeto do Biá tem, no seu inventário de marcas indicando uma relação espacial, um sufixo -na de alativo, que até agora só foi observado uma vez nos dados do dialeto Kanamarí.

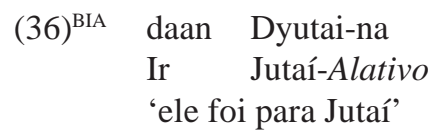

Observa-se este mesmo sufixo junto a um nome referindo-se a um participante no papel de destinatário ou beneficiário.

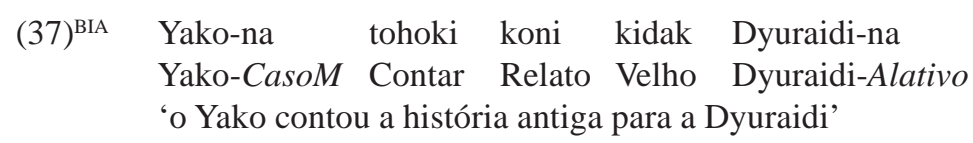

Frisamos que este sufixo alativo poderia ter originado a única marca de caso identificada na língua, que aparece no genitivo e no ergativo dos núcleos divalentes respectivamente nominal e verbal, assim como no complemento da posposição. Baseamos nossa hipótese em:

1) na verossimilhança de derivas semânticas, documentadas em outras línguas (Allen 1964, Gildea 2002), tais como:

$$
\text { alativo } \rightarrow \text { destinatário } \rightarrow \text { possuidor } \rightarrow \text { agente }
$$


2) numa maior afinidade desta marca com o que costuma ser chamado de caso: à diferença das posposições, -na não rege um sintagma nominal marcado para caso, nem aceita o paradigma de prefixos pessoais (cf. (15)). Uma generalização — não semântica, e sim estrutural - de marca de genitivo/ergativo para marca de argumento interno seria responsável da extensão de -na ao complemento de posposição.

A seguir algumas informações a mais sobre cada tipo de sintagma.

O sintagma verbal na construção acusativa aparece em (7), repetido aqui.

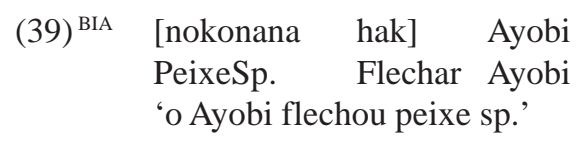

Seu argumento interno não pode ser pronominalizado no dialeto Biá. No dialeto Kanamarí, essa possibilidade só foi atestada em material elicitado. (É de se lembrar a hipótese da genericidade do argumento interno na construção acusativa).
$(40)^{\mathrm{ITQ}} \quad$ [anyan duni] mapiri
Ele Pegar Cobra
'a cobra o pegou'

No sintagma nominal, há duas construções genitivas, a de (32) e (33), compacta, é própria dos núcleos nominais divalentes ("posse inalienável"). Com nomes monovalentes ("posse alienável") temos uma construção analítica, em que um nome genérico relacional wa, divalente e com significado "bem, coisa possuída", gera como núcleo um sintagma nominal em que o "possuidor" é seu argumento interno.

\section{$(41)^{\mathrm{ITQ}} \quad$ Hanani-na wa \\ Hanani-CasoM Bem \\ 'o da Hanani'}

(No dialeto Biá o -na tem alomorfismo aqui).
$(42)^{\text {ITQ }} \quad$ a-wa
$3^{\circ}$ Singular-Bem
'o dele'

O nome do "possuído" aparece após esse sintagma (em uma posição sintática que não é exatamente a de núcleo, menos ainda a de aposição, cf. Queixalós 2005).
(43) $)^{\mathrm{ITQ}} \quad$ [Yowi-na wa] hak Yowi-CasoM Bem
'a casa do Yowi' 


$\begin{array}{lll}(44)^{\mathrm{ITQ}} & \text { [a-wa }] & \text { hak } \\ & 3^{\circ} \text { Singular-Bem } & \text { Casa } \\ & \text { 'a casa dele' } & \end{array}$

A seqüência prefixo pessoal + wa é mais opaca ou irregular nas outras pessoas, o que pode ser visto como o sintoma da criação de um paradigma de determinantes possessivos independente do paradigma de prefixos pessoais.

(45)

$\begin{array}{lll} & \text { singular } & \text { plural } \\ 1^{\text {o }} & \text { atya } & \text { ityowa } \\ 2^{\text {o }} & \text { inowa } & \text { idiki-na wa } \\ 3^{\text {o }} & \text { a-wa } & \text { ma-wa }\end{array}$

O sintagma posposicional tem uma forma alternativa à de (6), retomada aqui:

\begin{tabular}{|c|c|c|c|}
\hline & $\begin{array}{l}\text { [Yako-na } \\
\text { Yako-CasoM }\end{array}$ & $\begin{array}{l}\text { katu] } \\
\text { ComitativoInstrumental }\end{array}$ & $\begin{array}{l}\text { Dyuraidi } \\
\text { Dyuraidi }\end{array}$ \\
\hline
\end{tabular}

Com efeito, há situações em que o argumento interno perde a marca de caso. A identificação dos condicionamentos para esse fenômeno está em andamento, mas parece envolver alguns nomes não humanos (47), e, particularmente, nomes de lugar (48).

$(47)^{\mathrm{ITQ}}$ Yowai-na toman mok [mokawa katu]

Yowai-CasoM Atirar Anta Espingarda ComitativoInstrumental

'Yowai atirou na anta com a espingarda'

$(48)^{\text {ITQ }}$ dapuki adu [dan ton]

Cair Eu Caminho Locativo

'eu caí pelo caminho'

A seguir alguns complementos de informação sobre morfologia verbal e nominal.

Os verbos apresentam um paradigma de dois sufixos direcionais dêiticos, aplicados principalmente a eventos envolvendo deslocamento ou localização espacial:

$$
\begin{array}{ll}
\text { centrípeto }^{7} & \text { centrífugo } \\
\text {-di } & \text {-na }
\end{array}
$$

$(50)^{\text {BIÁ }}$ Ayobi waok-di

Ayobi Chegar-Centrípeto

'Ayobi chegou (aqui)'

\footnotetext{
${ }^{7}$ No dialeto Kanamarí o centrípeto é -dyi.
} 


\author{
$(51)^{\mathrm{ITQ}}$ na:tyi hi:k-na \\ Milho Buscar-Centrífugo \\ 'ele foi buscar milho' \\ $(52)^{\mathrm{ITQ}} \quad$ tyuku-na \\ Morrer-Centrífugo \\ 'morreu para lá'
}

Um sufixo de aspecto -nin indica extensão do evento no tempo.

$(53)^{\mathrm{ITQ}} \quad$ koya $\quad$ Nodia-na o-nin

Caiçuma Nodia-CasoM Beber-Durativo

'Nodia está bebendo caiçuma'

Ele é habilitado a gerar formas não finitas do verbo (particípio, predicado subordinado, etc.).

$\begin{array}{llll}(54)^{\mathrm{ITQ}} & \begin{array}{l}\text { Nodia-na tohi:k } \\ \text { Nodia-CasoM Ver }\end{array} & \text { Homem } & \text { wapa-nin } \\ \text { 'Nodia olha o homem roçando' } & \end{array}$

Nas construções auxiliares, tais como:
kitan-nin
bak
Dormir-Subordinador SerBom
'ele dormiu muito'

ele se procliticiza ao auxiliar.

Os sufixos de negação e de durativo-subordinação aparecem nessa ordem, como ilustra o exemplo a seguir:

Do lado dos nomes, um pequeno paradigma sufixado de classificadores fornece informação relativa à forma ou à substância da entidade referida. Sua distribuição precisa ser mais estudada. Exemplos de classificadores identificados até agora são:
doroko-an
Flecha-Comprido
'flecha'

koraman-an

CobraSp.-Comprido

'cobra sp.' 
(58)

katyaha-hi
Cachaça-Líquido
'cachaça'

(59)

batyi-hai

Veado-SubstânciaMole

'carne de veado'

(60) mokawa-kon

Espingarda-Cilindro

'cartucho' pi:-hi

Espinho-Líquido

'veneno'

iko-mi-hai

Olho-Buraco-SubstânciaMole

'humor aquoso'

oba-kon

Tabaco-Cilindro

'cigarro'

Um sufixo -pa deriva verbos intransitivos de nomes. Seu papel consiste em introduzir dinamicidade na noção nominal. O resultado é com frequiência "se tornar N", como em (61), mas não necessariamente, como em (62) e (63):

$(61)^{\text {BIA }} \quad$ wa:ro-pa

Papagaio-Verbalizador

'ele virou papagaio'

(62) ${ }^{\text {ITQ }} \quad$ waik-pa

Canto-Verbalizador

'ele canta'

$(63)^{\mathrm{ITQ}}$ bora-pa ityaro hinuk

Bola-Verbalizador Mulher Grupo

'as mulheres brincam de bola'

Outrossim, nem todas as suas ocorrências envolvem dinamicidade:

$\begin{array}{ll}(64)^{\text {BIA }} & \text { Ayobi pi:da-pa } \\ & \text { Ayobi Onça-Verbalizador } \\ & \text { 'Ayobi parece com onça' }\end{array}$

Esse sufixo poderia se originar, diacronicamente, de um verbo -pa de significado abstrato "realizar" ainda vivo hoje em dia:

$(65)^{\mathrm{ITQ}}$ waik baknin tyo-pa

Canto Bom $1^{\circ}$ Plural-Realizar

'nós cantamos música bonita'

Passamos agora a examinar as três classes restantes de palavras: adjetivos, advérbios e partículas. A sua característica comum é carecer de flexão e também da capacidade de ser núcleo de sintagma. 
A existência da classe dos adjetivos é ainda duvidosa. Muitas noções qualitativas são expressas nessa língua mediante verbos intransitivos.

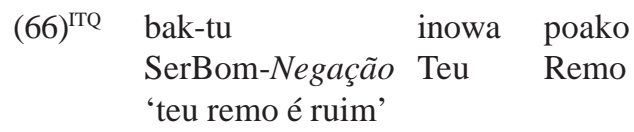

Particípios desempenham com freqüência o papel de modificadores de núcleos nominais. É o caso de (65), reanalisado aqui:
$(67)^{\mathrm{ITQ}}$
$\begin{array}{ll}\text { [waik bak-nin] } & \text { tyo-pa } \\ \text { Canto } & \text { SerBom-Subordinador } \\ 1^{\circ} \text { Plural-Realizar } \\ \text { 'nós cantamos música bonita' }\end{array}$

No entanto, existem formas lexicalmente primitivas cuja vocação é modificar um núcleo nominal:

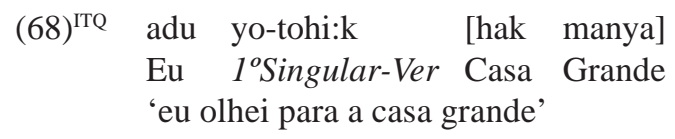

Tais vocábulos, únicos bons candidatos a terem o estatuto de adjetivos, são raros nos dados disponíveis até hoje. Se levarmos em conta o caráter nitidamente marcado do Katukína como língua de núcleo final, merece atenção a posição pós-nominal das formas adjetivais observáveis em (67) e (68). No sintagma nominal, não só o genitivo de "posse", visto em (32) e (43), se conforma à ordem canônica modificador + modificado, mas também todos os outros complementos nominais:

\begin{tabular}{|c|c|c|c|c|c|c|c|}
\hline (69) ${ }^{\mathrm{ITQ}} \mathrm{ka}$ :dyo & $\begin{array}{l}\text { dak } \\
\text { Couro }\end{array}$ & $\begin{array}{r}\text { kotyia } \\
\text { Lontra }\end{array}$ & $\begin{array}{l}\text { padakon } \\
\text { Ovo }\end{array}$ & $\begin{array}{l}\text { taropu } \\
\text { Côco }\end{array}$ & $\begin{array}{l}\text { pi: } \\
\text { Espinho }\end{array}$ & $\begin{array}{l}\text { kupaman } \\
\text { Paxiúba }\end{array}$ & $\begin{array}{l}\text { dak } \\
\text { Casa }\end{array}$ \\
\hline 'cour & caré' & \multicolumn{2}{|c|}{ 'testículo de ariranha' } & \multicolumn{2}{|c|}{ pinho de coco' } & & \\
\hline
\end{tabular}

Uma hipótese, a ser verificada, seria que o "adjetivo" de (68) e o "particípio" de (67) sejam, afinal de contas, elementos nominais em função de núcleo, da mesma maneira que "fêmea" e "dois" nos exemplos a seguir:
(70) ${ }^{\mathrm{ITQ}} \quad$ pi:da wa
Onça Fêmea
'onça fêmea'
paiko obawa
Homem Dois
'dois homens (cf. dupla de homens')

A classe dos advérbios é mais claramente estabelecida. Eles veiculam principalmente semantismos de localização espacial e temporal. 


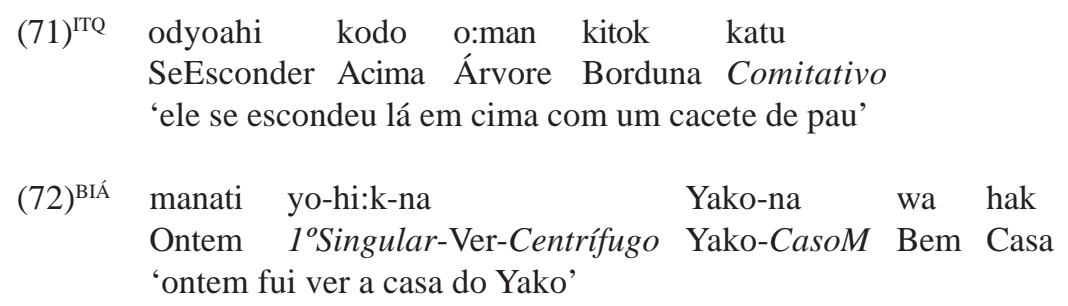

Para encerrar esta seção, examinamos a classe das partículas, possivelmente a parte mais difícil de se analisar na gramática Katukína. Excetuando a marca de durativo -nin, também utilizada na subordinação dos predicados, toda a informação temporal, aspectual e modal da oração passa pelos advérbios e pelas partículas. Sobra dizer que na hora da análise, a fronteira entre advérbios e partículas não é sempre fácil de identificar, embora os advérbios tenham propensão a formar palavras de duas ou três sílabas, enquanto as partículas são geralmente monossilábicas. O estudo da distribuição, do âmbito de influência ("escopo") e do significado das partículas está por se fazer. Muitas delas tendem a aparecer em final de oração, como a marca de prospectivo ou a marca de exclamação:

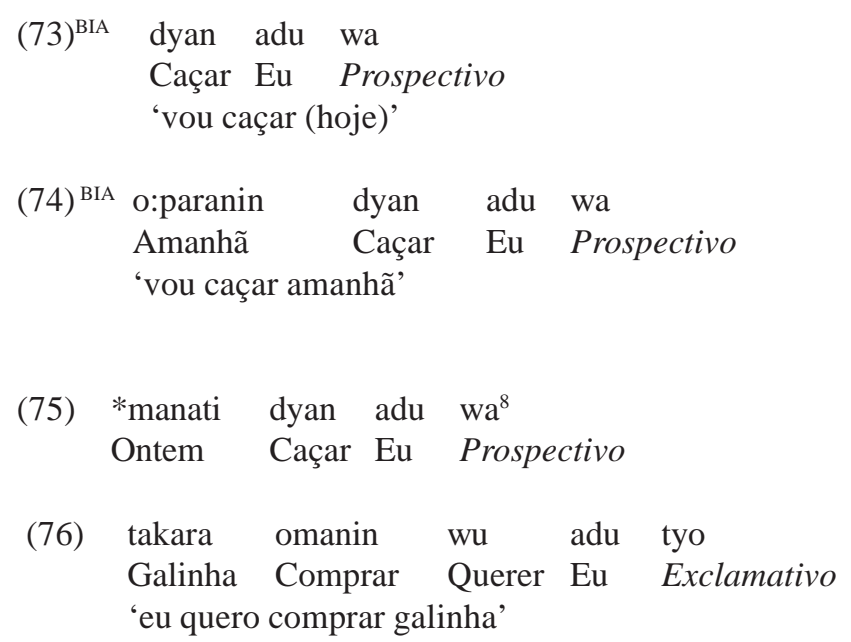

Vejam-se a seguir dois fragmentos de relatos espontâneos. A tradução é tal qual foi fornecida pelo informante. Tudo o que fica sem glosa justalinear é partícula, cuja função é indicar noções gramaticais de tempo, aspecto, modo, ou assegurar a coesão do discurso.
$(77)^{\mathrm{ITQ}}$ adi:k kotu da antunin kotu da ti
Nós
ityowa ityonin naki kotu da ti $[\ldots]$
'ficamos aqui no nosso mato'
Nossa Floresta Em

\footnotetext{
$8 *$ Construção agramatical.
} 


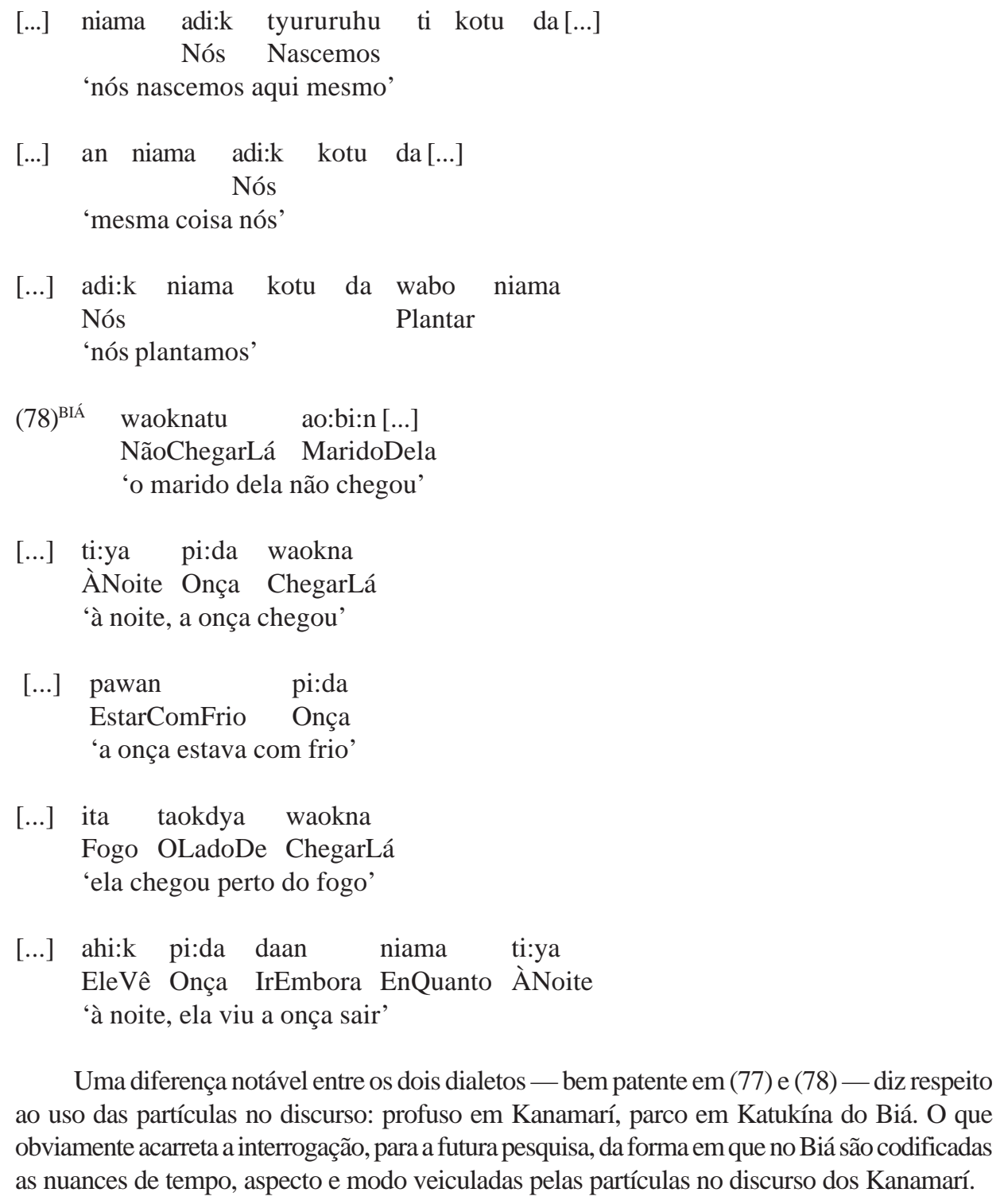

Uma diferença notável entre os dois dialetos — bem patente em (77) e (78) — diz respeito ao uso das partículas no discurso: profuso em Kanamarí, parco em Katukína do Biá. O que obviamente acarreta a interrogação, para a futura pesquisa, da forma em que no Biá são codificadas as nuances de tempo, aspecto e modo veiculadas pelas partículas no discurso dos Kanamarí.

\section{LÉXICO}

Nesta seção almejamos apresentar uma breve comparação lexical entre os dois dialetos, descriminando os casos de: 1) palavras idênticas, 2) palavras cognatas não idênticas e 3) palavras totalmente diferentes. A nossa impressão preliminar sobre o léxico das duas variedades é que na imensa maioria dos casos as palavras ou são idênticas ou são semelhantes. 
1)

Katukína do Biá Kanamarí

2)

$\begin{array}{ll}\text { wa:ro } & \text { wa:ro } \\ \text { ka:dyo } & \text { ka:dyo } \\ \text { wakak } & \text { wakak } \\ \text { makona } & \text { makona } \\ \text { wa:dyo } & \text { wa:dyo }\end{array}$

'papagaio'

'jacaré'

'abacaxi'

'cará'

'macaco preto'

payo
nayo
payo ki:dak
kidyokon
oparanin

pama

'pai'

nyama

paiko

kiwadyo

paradyi

'mãe'

'avô'

'passarinho'

'amanhecer'

3)

nayo ki:dak
aka:ka
arawiri
anya
wu:dyon

wa

amona

tyoroi

obatyawa

itakirakon 'avó'

'macaco acari'

'sardinha'

'mulher'

'Iontra

\section{TEXTO}

À guisa de ilustração da análise lingüística oferecida no que precede, apresentamos para encerrar um breve relato coletado no Biá em 2004 por Dos Anjos (informante Kopa Antônio, 35 anos). Nas notas de rodapé apontamos as lacunas que ainda subsistem na compreensão da gramática da língua.

(79) Yutai odian konan mok

Jutai OutroLado Beira Anta

'a anta estava na beira do outro lado do rio Jutai'

(80) Yoao $^{9}$ ma:pikan mok dya-nin ${ }^{10}$

João Ouvir Anta Assobiar-Durativo

'João ouviu a anta assobiando'

(81) ti:-di, daan, adi:k too ${ }^{11} \quad$ hadi $^{12}$ mok

Voltar-Centrípeto Ir Nós Outro Pegar Anta

'voltou para cá, veio para que nós fossemos pegar a anta'

${ }^{9} \mathrm{O}$ verbo "ouvir" sendo divalente, o seu argumento interno Yoao devia ter sufixado a marca de caso -na.

${ }^{10}$ Este é um caso típico de subordinação de verbo mediante o sufixo aspectual -nin.

${ }^{11}$ Aqui também, o argumento interno de "pegar", "outro", devia levar a marca de caso -na.

${ }^{12}$ Falta marca de subordinação no verbo. 
(82) daan $^{13}$

Ir

'Saímos'

(83) po:dak iki-na woikan mok patu-na tyo-waraboi ${ }^{14}$ mok

Canoa Dentro-Alativo Remar Anta Lugar-Alativo $1^{\circ}$ Plural-Matar Anta

'Fomos remando na canoa para o lugar onde estava a anta, para matá-la'

(84) wa:pa ${ }^{15}$, a-yoman mok

Cachorro $3^{\circ}$ Singular-Latir Anta

'o cachorro, ele latiu para a anta'

(85) wa:hi iki mok

Rio Dentro Anta

'a anta estava dentro do rio'

(86) yo-hoinin ma-hak ${ }^{16} \quad$ arapão katu $^{2}$

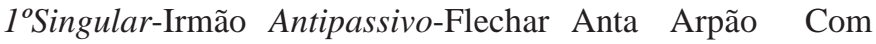
'meu irmão acertou a anta com o arpão'

(87) Ayobi-na boni mok obawa-nin $\mathrm{ti}^{17}$

Ayobi-CasoM Furar Anta SerDois ${ }^{18}$-Durativo Partícula

'Ayobi furou a anta três vezes'

(88) tyuku mok

Morrer Anta

'a anta morreu'

(89) tyo $^{19}$ woikwoik maratyinin-na

Nós Remar Praia-Alativo

'nós remamos para a praia'

${ }^{13}$ É bem freqüente a omissão dos pronomes de primeira pessoa quando eles cumprem a função de argumento externo de predicado monovalente.

${ }^{14}$ Falta marca de subordinação no verbo.

${ }^{15}$ Este sintagma nominal está extraposto à esquerda, como mostra a falta de sufixo de caso e a presença do prefixo de terceira pessoa singu

lar no verbo.

${ }^{16}$ Este é um exemplo de construção antipassiva com explicitação lexical do paciente.

${ }^{17}$ A natureza desta partícula é ainda obscura. Ela parece ter um significado básico de "pequenez", e seria usada também modalmente para indicar ora exatidão em uma localização espacial, ora comiseração.

${ }^{18}$ Ignoramos porque o informante traduz "três" sendo que os outros dados dão a obawa o significado "dois".

19 Tanto nos dados do Biá quanto nos do Itaquai, tyo é um prefixo de primeira pessoa plural. Observamo-lo na penúltima oração deste relato. Já no Biá, ele parece ser também uma forma pronominal livre, junto com adi:k. 
(90) bo:tyi patu-na toti:k mok

Bote Lugar-Alativo Embarcar Anta

'a anta foi para dentro do bote'

(91) motor ton do:kan adi:k

Motor Com Rebocar Nós

'nós andamos de reboque com o motor de rabeta'

(92) tan ti waok adi:k wanao $^{20}$ ton

Aqui Partícula Chegar Nós Porto Em

'nós chegamos aqui no porto'

(93) anya iki wanao ton yan paya

Mulher Dentro Porto Em ? Esperar

'as mulheres estavam esperando no porto' ${ }^{21}$

(94) anya iki wa-tohi: $\mathrm{k}^{22}$ mok

Mulher Dentro Antipassivo-Olhar Anta

'as mulheres estavam olhando a anta'

(95) da:tya:ni-di mok

IrArrastado-Centrípeto Anta

'a anta veio arrastada'

(96) tyo-pi:k mok

$1^{\circ}$ Plural-Cortar Anta

'cortamos a anta'

(97) daan-di

Ir-Centrípeto

'viemos para cá'

${ }^{20}$ Não temos certeza que esta seja a forma fonológica de "porto".

${ }^{21}$ A forma yan é desconhecida para nós. Outrossim, não vemos com claridade o mecanismo mediante o qual a posposição "dentro" induz um significado coletivo "mulherada" (tradução do informante).

${ }^{22}$ Mais um exemplo de construção antipassiva com explicitação lexical do paciente. 


\section{REFERÊNCIAS BIBLIOGRÁFICAS}

ADELAAR, Willem F. (2000). Propuesta de un nuevo vínculo genético entre dos grupos lingüísticos indígenas de la amazonía occidental: harakmbut y katukína. In Luis Miranda (ed.). Actas del I Congresso de Lenguas Indígenas de Sudamérica, pp. 337-343. Lima: Universidad Ricardo Palma.

ALLEN, W. (1964). Transitivity and possession. Language 40: 337-343.

CARVAlHO, Maria do Rosário G. (1998). Os Kanamarí da Amazônia Ocidental: história e etnografia. Tese de Doutorado. São Paulo: USP

.(2002). Os Kanamarí da Amazônia Ocidental: história, mitologia, ritual e xamanismo. Salvador: FCJA.

DOS ANJOS, Zoraide. A língua Katukína. (2005a). Caderno do Simpósio de Letras: múltiplos olhares. Goiânia: Universidade Federal de Goiás.

(2005b). Fonologia Katukína (dialeto Katukína do Biá). Dissertação de Mestrado. Brasília Universidade de Brasília.

FUNAI (1988). (Documento interno)

GILDEA, S. (2002). Ergativity in the Northern Cariban Languages. In F. Queixalós (org.) Ergatividade na Amazônia I, Atas do primeiro encontro do projeto Manifestações da ergatividade na Amazônia, pp. 137-145. Brasília: Universidade de Brasília.

GROTH, Christine. (1977). Here and There in Kanamarí. Anthropological Linguistics 19(5): 203-215 (1985). Syntax of the phrase types in Canamarí. In David L. Fortune (ed.). Porto Velho Workpapers, pp. 93-129. Brasília: SIL.

.(1988a). Modo y aspecto en el discurso kanamarí. Revista Latinoamericana de Estudios Etnolingüísticos 5: 51-72.

.(1988b). Prominencia, evaluación y el uso de la partícula tso en el discurso kanamarí. Revista Latinoamericana de Estudios Etnolingüísticas 5: 73-91

LABIAK, Araci Maria. (1997). Frutos do céu e frutos da terra: aspectos da cosmologia Kanamarí no Warapekom. Dissertação de Mestrado. Florianópolis: UFSC.

LIMA, Deborah \& PY-DANIEL, Victor. (2002). Levantamento etnoecólogico das áreas indígenas Kanamarí do Médio Juruá e Katukína rio Biá: relatório final. Brasília, FUNAI/ PPTAL.

LOUKOTKA, Èestmir. (1949). Sur quelques langues inconnues de l'Amérique du Sud. Língua Posnianensis 1: 53-82. Posnan.

.(1963). Documents et vocabulaires inédits de langues et de dialectes sud-américains. Journal de la Société des Américanistes 52: 7-60.

MARTIUS, Karl Friederich Phillip von. (1863). Glossaria Linguarum Brasiliensium. Glossário de diversas lingoas e dialectos que fallao os indios no imperio do Brazil.Wörtersammlung brasilianischer Sprachen. Erlangen: Druck von Junge \& Sohn.

MONTEIRO, Rosa Maria. (2002). Wana Adjaba itsonim nawara (os donos da terra). In Márcia Maria Gramkow (org.) Demarcando terras indígenas II: experiências e desafios de um projeto de parceria. Brasília, pp. 207-222. FUNAI/PPTAL/GTZ. 
NEVES, Lino J. Oliveira. (1996). 137 anos de sempre: um capítulo da história Kanamarí do contato. Dissertação de Mestrado. Florianópolis: UFSC.

OPAN. (2000). Relatório de Viagem, povo indígena Katukína. Jutaí. (ms.)

QUEIXALÓS, Francesc. (1995). Transitividade em Katukína: uma primeira aproximação. Anais do IX Encontro nacional da ANPOLL, Lingüística, vol. 2: 1063-1071. João Pessoa-PB.

.(2002a). Sobre um sujeito Katukína e um objeto Sikuani. In A. S. Cabral, \& A. D. Rodrigues, (eds.) Atas do I Encontro Internacional do Grupo de Trabalho sobre Línguas Indígenas da ANPOLL, tomo II, pp. 260-270. Belém: UFPA

.(2002b). Ergatividade em Katukina in Queixalós, F. (org.). Ergatividade na Amazônia I, Atas do primeiro encontro do projeto Manifestações da ergatividade na Amazônia. Brasília, Universidade de Brasília, 2002b, páginas 137- 145.

.(2003). A ergatividade Katukína em frente das mudânças de valência. In F. Queixalós (org.) Ergatividade na Amazônia II, Atas do segundo encontro do Projeto Manifestações da ergatividade na Amazônia, pp. 227-237. Brasília: Universidade de Brasília.

.(2004). Split Transitivity and Coreference in Katukína. In F. Queixalós, F. (org.). Ergatividade na Amazônia III, Atas do terceiro encontro do Projeto Manifestações da ergatividade na Amazônia, pp. 175-188. Paris: CNRS.

.(2005). Posse em Katukina e valência dos nomes. In A. D. Rodrigues \& A. S. Cabral, A.(orgs.). Novos estudos sobre línguas indígenas brasileiras, pp. 177-202. Brasília: Universidade de Brasília. Incorporation in katukína-kanamarí. Amerindia (no prelo).

REESINK, Edwin B. (1993). Imago Mundi Kanamarí. Tese de Doutorado. Rio de Janeiro: UFRJ-Museu Nacional.

RIBEIRO, Adelina et al. (1989). Elementos da fonologia Kanamarí. Cadernos de Estudos Lingüísticos 16: 123-141. Campinas: IEL/UNICAMP.

RIVET, Paul. (1920). Les Katukína, étude linguistique. Journal de la Société des Américanistes 12: 83-89.

RODRIGUES, Aryon. (1986). Línguas brasileiras: para o estudo das línguas indígenas. São Paulo: Loyola.

SANTOS, Lenize Maria Wanderley. (2002). STRS autossômicos e ligados ao cromossomo y em indígenas brasileiros. Universidade de São Paulo/FMRP. Tese de Doutorado.

TASTEVIN, Constantin. (1920a). Vocabulaire Katawixí et Marawa. Manuscritos dos Arquivos da Congregação do Santo Espírito, Chevilly-Larue.

.(1920b). Le fleuve Juruá. La Géographie. Paris, Société de Geographie, exemplar de janeiro, pp.1-23.

.(1927). La région du Moyen-Amazone ou Solimões (Brésil). La Géographie. Paris, Société de Geographie, exemplares de novembro e dezembro, pp. 259-281.

(1928). Le Riozinho da Liberdade. La Géographie. Paris, Société de Geographie, exemplar de abril, 1928, pp. 1-12. 
TOVAR, A. (1961). Catálogo de las lenguas de América del Sur. Buenos Aires: Editorial Sudamérica.

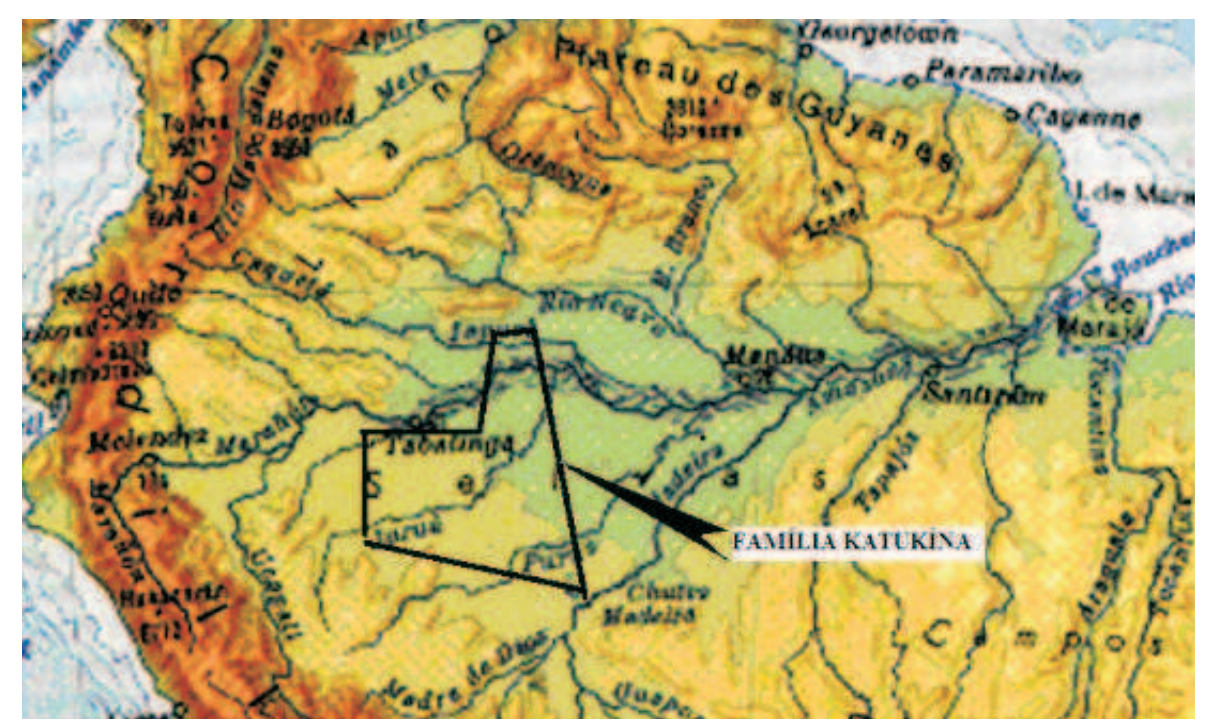

Recebido: 05/07/2006

Versão revista: 15/08/2006

Aceito:30/11/2006. 